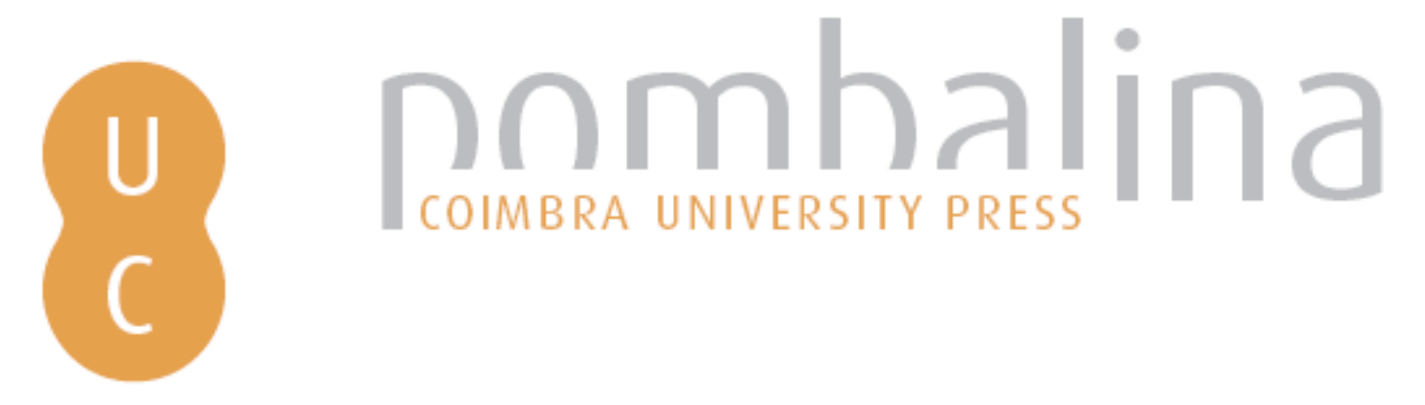

\title{
Modificação das propriedades hidráulicas dos solos da Serra algarvia devido aos incêndios florestais
}

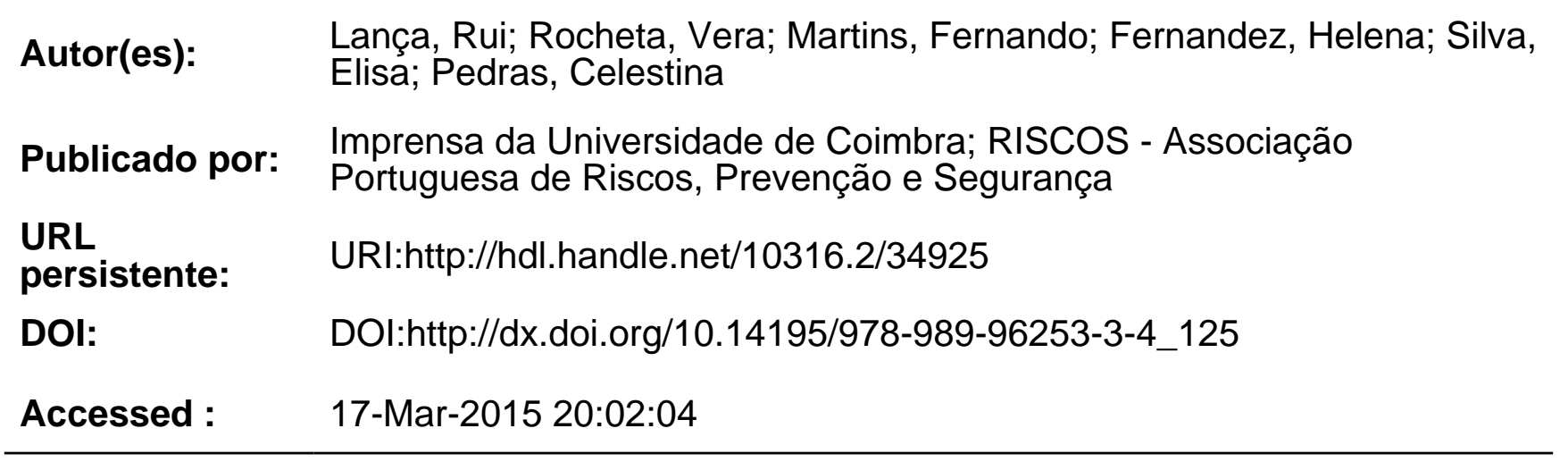

A navegação consulta e descarregamento dos títulos inseridos nas Bibliotecas Digitais UC Digitalis, UC Pombalina e UC Impactum, pressupõem a aceitação plena e sem reservas dos Termos e Condições de Uso destas Bibliotecas Digitais, disponíveis em https://digitalis.uc.pt/pt-pt/termos.

Conforme exposto nos referidos Termos e Condições de Uso, o descarregamento de títulos de acesso restrito requer uma licença válida de autorização devendo o utilizador aceder ao(s) documento(s) a partir de um endereço de IP da instituição detentora da supramencionada licença.

Ao utilizador é apenas permitido o descarregamento para uso pessoal, pelo que o emprego do(s) título(s) descarregado(s) para outro fim, designadamente comercial, carece de autorização do respetivo autor ou editor da obra.

Na medida em que todas as obras da UC Digitalis se encontram protegidas pelo Código do Direito de Autor e Direitos Conexos e demais legislação aplicável, toda a cópia, parcial ou total, deste documento, nos casos em que é legalmente admitida, deverá conter ou fazer-se acompanhar por este aviso.

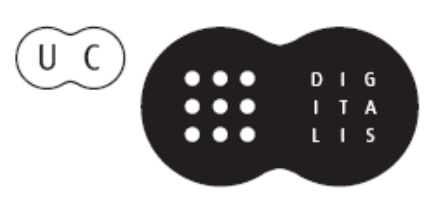



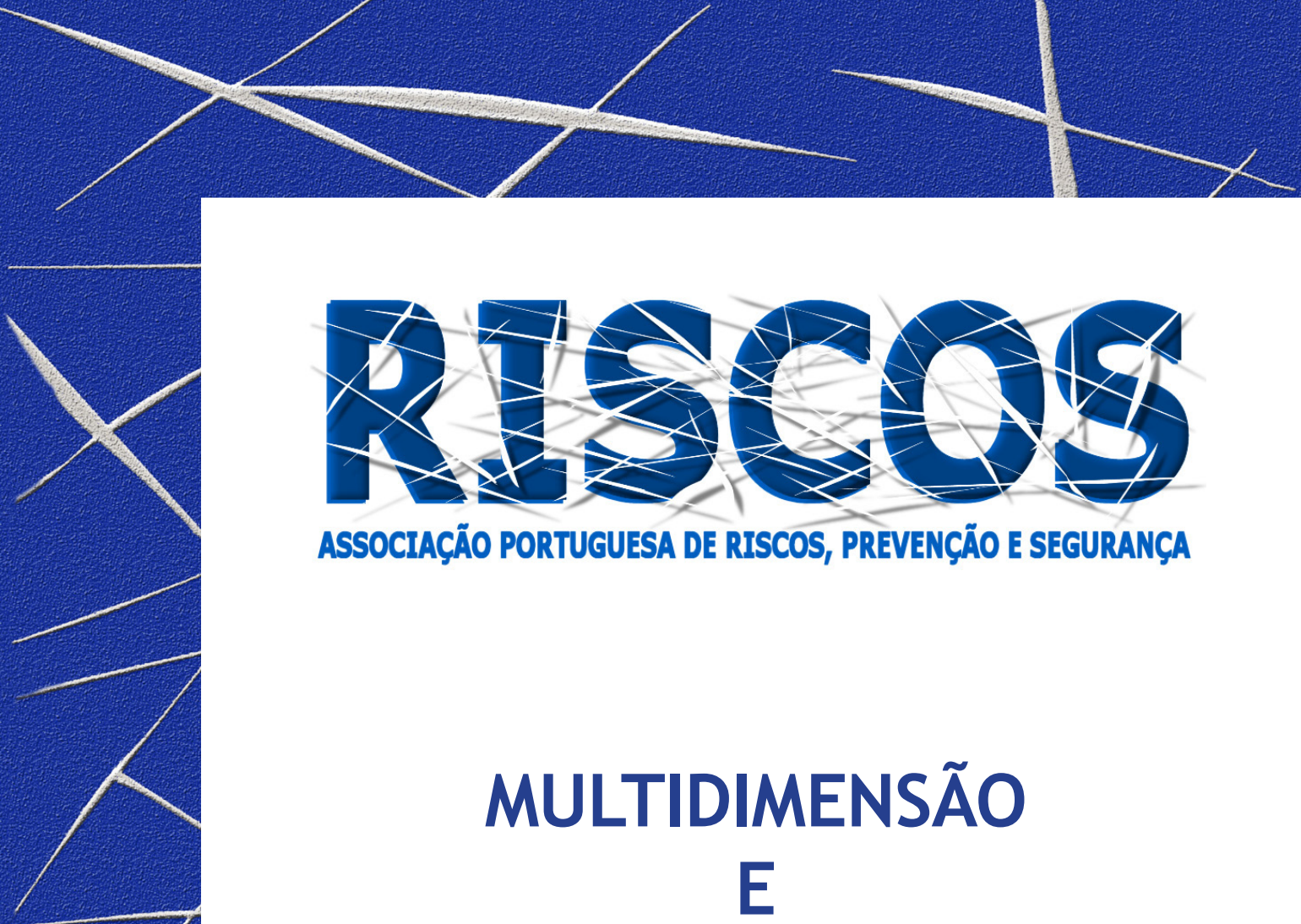

ASSOCIAÇÃO PORTUGUESA DE RISCOS, PREVENCCÃO E SEGURANÇA

MULTIDIMENSÃO

E
TERRITÓRIOS DE RISCO

III Congresso Internacional

I Simpósio Ibero-Americano

VIII Encontro Nacional de Riscos

Guimarães

2014 


\title{
MODIFICAÇÃO DAS PROPRIEDADES HIDRÁULICAS DOS SOLOS DA SERRA ALGARVIA DEVIDO AOS INCÊNDIOS FLORESTAIS
}

\author{
Rui Lança \\ Instituto Superior de Engenharia, Universidade do Algarve \\ rlanca@ualg.pt \\ Vera Rocheta \\ Instituto Superior de Engenharia, Universidade do Algarve \\ vrocheta@ualg.pt \\ Fernando Martins \\ Instituto Superior de Engenharia, Universidade do Algarve \\ fmmartin@ualg.pt \\ Helena Fernandez \\ Instituto Superior de Engenharia, Universidade do Algarve \\ hfernand@ualg.pt \\ Elisa Silva \\ Instituto Superior de Engenharia, Universidade do Algarve \\ esilva@ualg.pt \\ Celestina Pedras \\ Faculdade de Ciências e Tecnologia, Universidade do Algarve \\ cpedras@ualg.pt
}

\begin{abstract}
RESUMO
Os incêndios florestais produzem um solo extremamente seco coberto por cinza, resultante da combustão do coberto vegetal, que quando exposto a precipitações intensas pode dar origem a inundações extremas. As inundações após incêndio poderão estar relacionadas com a diminuição da capacidade de infiltração do solo, efeito resultante da colmatação e preenchimento por compostos voláteis dos poros e depósito da camada de cinza na superfície. Para caracterizar a condutividade hidráulica, $\mathrm{k}_{\mathrm{s}}$, e a sorvidade, $\mathrm{S}$, foram realizados ensaios laboratoriais com um infiltrómetro de duplo anel em amostras de solo não perturbadas.

Para o efeito foram recolhidas 4 amostras não perturbadas de solo característico da serra algarvia, com as dimensões $50 \times 50 \times 25 \mathrm{~cm}$. Sobre 3 amostras, foram colocadas diferentes quantidades de material combustível, conduzindo a diferentes quantidades de cinza. Posteriormente, foram realizados ensaios com um infiltrómetro de duplo anel na amostra de referência não ardida e nas 3 amostras afetadas pelo incêndio simulado em laboratório. Os resultados mostram diferentes valores de $\mathrm{k}_{\mathrm{s}}$, $\mathrm{S}$ e consequentemente diferentes valores da capacidade de infiltração do solo.
\end{abstract}

Palavras-chave: condutividade hidráulica; sorvidade; incêndio; solos ardidos.

\section{Introdução}

Os incêndios florestais induzem alterações no ciclo hidrológico através da diminuição da capacidade de infiltração do solo, aumento do volume e da velocidade do escoamento superficial, o que leva à diminuição do tempo de resposta da bacia hidrográfica e aumento do caudal de ponta de cheia. Estas alterações aumentam a vulnerabilidade de pessoas e bens às inundações.

A infiltração pode ser separada nos termos relativos à resposta curta e longa. A resposta curta depende da sorvidade, $\mathrm{S}$, e reflete o potencial de capilaridade. A resposta longa depende da condutividade hidráulica, $\mathrm{k}_{\mathrm{s}}$, e reflete o potencial por gravidade (Philip, 1957; Smith, 2002). Estas relações podem ser modeladas pela equação de Richardson, contudo, a solução analítica 
dificilmente obtém com exatidão a resposta de solos sujeitos ao calor, compostos químicos voláteis e cinzas geradas pelos incêndios florestais.

O calor a que o solo está sujeito durante um incêndio florestal é essencialmente gerado pela combustão da manta morta e pela vegetação de pequeno porte próxima da superfície (Ryan, 2002) e depende da carga de combustível e da duração da combustão. O fluxo de calor pode aumentar a repelência à água, na medida em que retira a água adsorvida no solo e volatiliza compostos químicos que penetram nos poros e condensam durante o arrefecimento, revestindo os mesmos. A cinza que se deposita na superfície também afeta a capacidade infiltração do solo.

O objetivo deste estudo foi a quantificação da variação da sorvidade e da condutividade hidráulica de um solo esquelético derivado de xistos, característico da serra algarvia, afetado por um incêndio em função de diferentes cargas de material combustível.

\section{Instalações experimentais e procedimentos}

Foram recolhidas 4 amostras de solo não perturbado na Serra do Caldeirão (coordenadas WGS84:

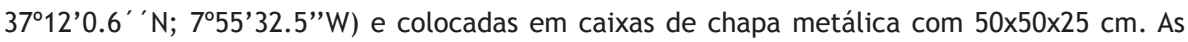
amostras foram cortadas, confinadas lateralmente (Figura 1a) e cortadas pela base por cravação de estacas de madeira na horizontal (Figura 1b). Posteriormente, foi inserida a base da caixa, construída em chapa metálica perfurada, entre as estacas e a amostra de modo a permitir o transporte.
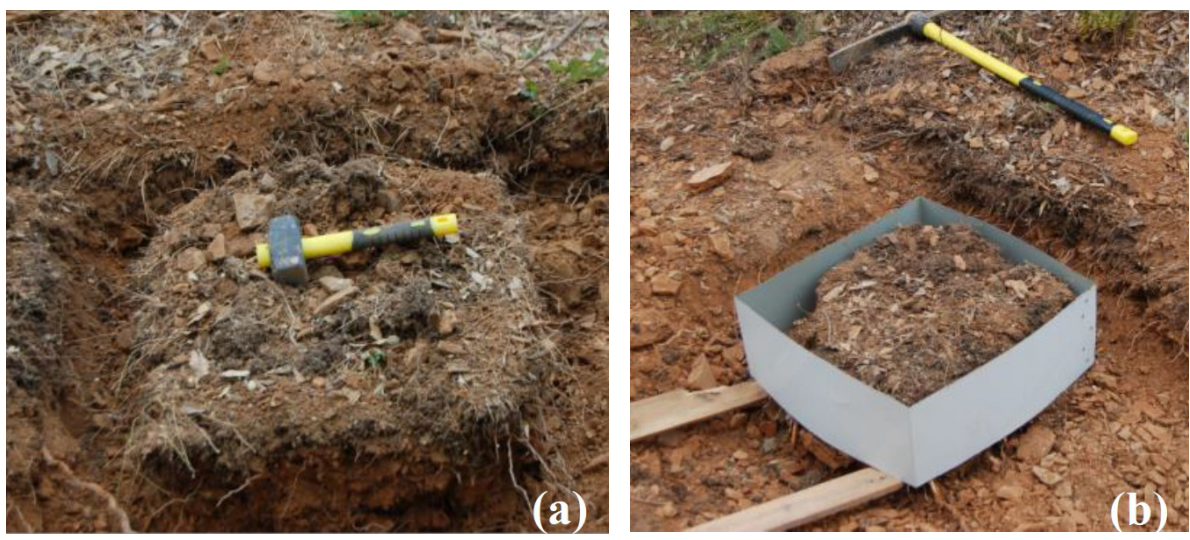

Figura 1 - Corte e preparação para transporte dos provetes

Os ensaios decorreram no Laboratório de Hidráulica do Departamento de Engenharia Civil do Instituto Superior de Engenharia da Universidade do Algarve. No Laboratório de Geotecnia desta mesma instituição determinou-se a granulometria do solo, verificando-se que este é constituído por $49 \%$ de cascalho anguloso, proveniente da erosão do xisto, $31 \%$ de partículas finas e $20 \%$ de areia. $\mathrm{O}$ ensaio granulométrico foi realizado após secagem do solo em estufa a $105^{\circ} \mathrm{C} \square 2^{\circ} \mathrm{C}$, durante 24 horas. Recorrendo ao método "Loss-on-Ignition" determinou-se, de igual modo, a percentagem e a quantidade de matéria orgânica do solo (MOS) sobre 6 amostras, antes da combustão, tendo-se obtido uma média que ronda as $26,51 \mathrm{gKg}^{-1}$, o que representa $2,65 \%$ em massa. 
Os ensaios para determinação da condutividade hidráulica e sorvidade foram realizados sobre 4 amostras com diferentes massas de material combustível, $M$, constituído principalmente por estevas e tojo. Na amostra A não foi colocado qualquer tipo de material combustível, enquanto sobre as restantes foram incendiadas e queimadas as seguintes massas: $M=1 \mathrm{~kg}$ na amostra $B$, $M=2 \mathrm{~kg}$ na amostra $C$ e $M=4 \mathrm{~kg}$ na amostra $D$. O Quadro I apresenta as variáveis características dos ensaios.

Quadro I - Variáveis características dos ensaios

\begin{tabular}{|l|l|l|l|l|}
\hline Amostra & A & B & C & D \\
\hline Material combustível total, M (kg) & 0 & 1 & 2 & 4 \\
\hline Teor em água no solo após combustão (\%) & 2,49 & 2,02 & 1,73 & 1,55 \\
\hline Duração da combustão (min) & -- & 19 & 16 & 18 \\
\hline Temperatura máxima durante a combustão $\left({ }^{\circ} \mathrm{C}\right)$ & -- & $>300$ & $>300$ & $>300$ \\
\hline
\end{tabular}

A taxa de infiltração foi medida com recurso a um infiltrómetro de duplo anel (Figura 2a) com diâmetro interior $20 \mathrm{~cm}$ e diâmetro exterior $30 \mathrm{~cm}$. Os anéis foram cravados até uma profundidade de $5 \mathrm{~cm}$. Durante o ensaio foi mantida uma carga hidráulica constante sobre a superfície do solo de $3 \mathrm{~cm}$, através de válvulas de nível, colocadas na alimentação ao anel interior e ao anel exterior (Figura 2b).
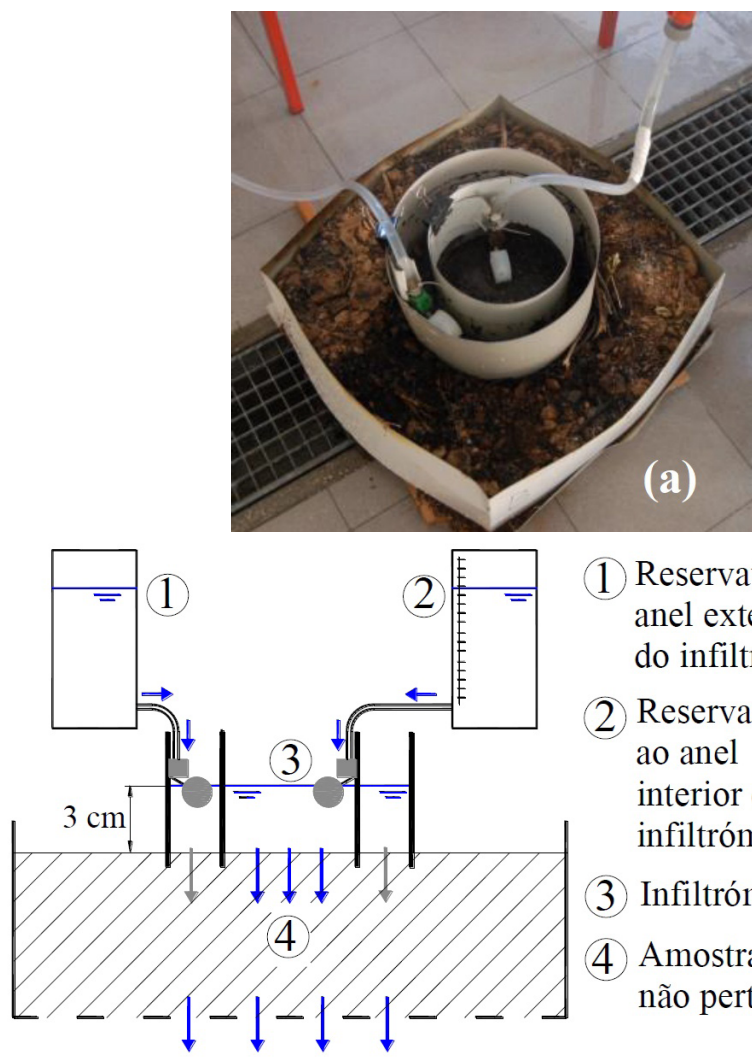

(1) Reservatório ligado ao anel exterior do infiltrómetro

(2) Reservatório ligado ao anel interior do infiltrómetro

(3) Infiltrómetro

(4) Amostra de solo não perturbado

Figura 2 - a) Ensaio com um infiltrómetro de duplo anel;

b) esquema hidráulico dos ensaios 
Foram realizadas medições do volume de água no reservatório que alimenta o anel interior a cada minuto durante a $1^{\text {a }}$ hora e a cada 5 minutos durante o resto do ensaio. Os ensaios tiveram durações aproximadas de 4 horas, instante a partir do qual a taxa de infiltração observada permaneceu aproximadamente constante.

\section{Resultados e discussão}

As taxas de infiltração observadas e as curvas $i=\varphi(t)$ obtidas por regressão logarítmica são apresentadas na Figura 3a. A Figura 3b apresenta as curvas de infiltração acumuladas, I, função da raiz quadrada do tempo, $\mathrm{t}^{0,5}$. Da regressão polinomial de segunda ordem das curvas da Figura 3 b, obtêm-se os valores da sorvidade, $\mathrm{S}$, e condutividade hidráulica, $\mathrm{k}_{\mathrm{s}}$, atendendo a que (Moody et al. 2009):

Com o aumento do material combustível e consequente aumento da camada de cinzas depositadas sobre o solo, observa-se uma diminuição da condutividade hidráulica, devido à presença das cinzas e outros produtos resultantes da combustão, e um aumento da sorvidade, que se relaciona com diminuição do teor em água no solo devido às elevadas temperaturas a que este está sujeito durante o incêndio.

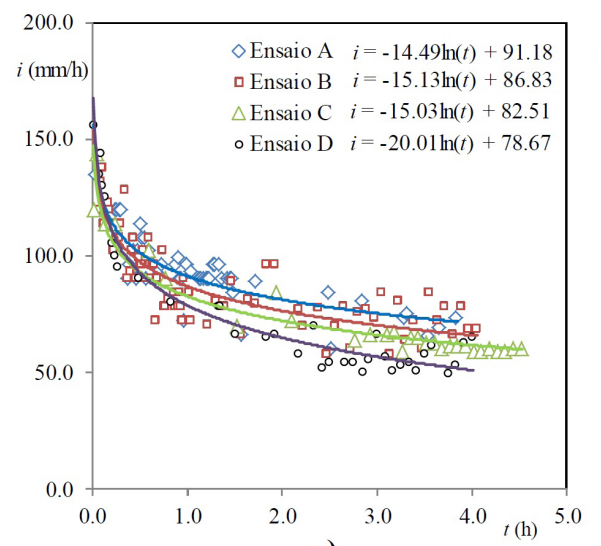

a)

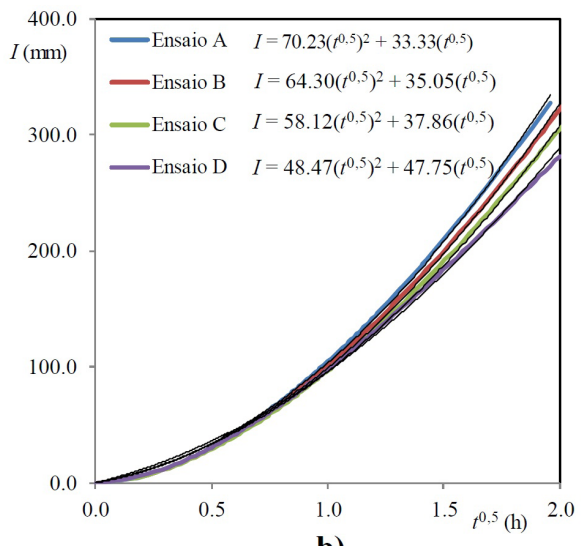

b)

Figura 3 - a) taxa de infiltração, i; b) infiltração acumulada, I como função da raiz quadrada do tempo, $\mathrm{t}^{0,5}$

Os valores de condutividade hidráulica, $\mathrm{k}_{\mathrm{s}}$, e de sorvidade, $\mathrm{S}$, estão apresentados no Quadro II. Os fatores da condutividade hidráulica, $\mathrm{K}_{\mathrm{ks}}$, e da sorvidade $\mathrm{K}_{\mathrm{s}}$, são função do material combustível, $M$, por unidade de área, $\mathrm{m}=\mathrm{M} / \mathrm{A}$, e foram obtidos de acordo com, $\left.\mathrm{K}_{\mathrm{ks}}=\mathrm{k}_{\mathrm{s}(\mathrm{m}=\mathrm{x}}\right)$ / $k_{s(m=0)}$ e $K_{s}=S_{(m=x)} / S_{(m=0)}$ em que $x$ representa um determinado valor de $m$. A aplicação dos fatores permitem corrigir os valores de referência de $k_{s}$ e $S$ dos solos não ardidos para solos ardidos em função de m. 
Quadro II - Valores de condutividade hidráulica, ks, e sorvidade, S, e respetivos fatores, Kks e KS

\begin{tabular}{|c|c|c|c|c|c|}
\hline Provete & $\begin{array}{c}\mathrm{m} \\
\left(\mathrm{kg} \mathrm{m}^{-2}\right)\end{array}$ & $\mathrm{k}_{\mathrm{s}} \quad\left(\mathrm{mm} \mathrm{h}^{-1}\right)$ & $\left.\mathrm{S} \quad{ }^{-0,5}\right)(\mathrm{mm}$ & $\mathrm{K}_{\mathrm{ks}}$ & $\mathrm{K}_{\mathrm{s}}$ \\
\hline $\mathrm{A}$ & 0 & 70.23 & 33.33 & 1.00 & 1.00 \\
\hline$B$ & 4 & 64.30 & 35.05 & 0.92 & 1.05 \\
\hline$C$ & 8 & 58.12 & 37.86 & 0.83 & $\frac{1.14}{1.14}$ \\
\hline D & 16 & 48.47 & 47.75 & 0.69 & 1.43 \\
\hline
\end{tabular}

Os resultados obtidos para $\mathrm{k}_{\mathrm{s}}$ e $\mathrm{S}$ poderão divergir dos resultados que se obteriam num ensaio de campo devido às diferentes condições de drenagem da base. Contudo é expetável que os fatores $\mathrm{K}_{\mathrm{ks}}$ e $\mathrm{K}_{\mathrm{s}}$ obtidos pelo rácio entre o respetivo ensaio e os resultados do ensaio de referência, amostra $A$, ambos realizados nas mesmas condições laboratoriais, traduzam o efeito da variação de $\mathrm{k}_{\mathrm{s}}$ e $\mathrm{S}$ de forma eficiente. Serão necessários mais ensaios experimentais em laboratório e no campo para sugerir um previsor da variação da capacidade de infiltração do solo devido a um incêndio florestal.

\section{Conclusão}

As inundações pós-incêndio poderão estar relacionadas com a diminuição da capacidade de infiltração da água no solo, efeito quer da secagem do solo, quer da deposição de cinzas resultante da combustão do coberto vegetal. Este estudo permitiu caracterizar a condutividade hidráulica e a sorvidade do solo da serra algarvia antes e após um incêndio, em ensaios em laboratório, em amostras de solo não perturbadas com um infiltrómetro de duplo anel.

Os resultados mostram que o aumento do material combustível, consequente ao aumento da camada de cinzas depositadas sobre o solo, leva a uma diminuição da condutividade hidráulica e um aumento da sorvidade. Mais ensaios experimentais serão necessários para sugerir um previsor do efeito da massa de material combustível na capacidade de infiltração do solo após incêndio. Este tipo de estudo poderá assim contribuir para melhorar o conhecimento da resposta das bacias hidrográficas a precipitações intensas após incêndio.

\section{Bibliografia}

Philip, J.R. (1957) - Theory of infiltration. In: Chow, V.T. (Ed.), Advances in Hydroscience, 5, New York . Academic Press, p. 215-296.

Ryan, K.C. (2002) - Dynamic interactions between forest structure and fire behavior in boreal ecosystems, Silva Fennica, 36 (1), Vantaa, p. 13-39.

Smith, R.E. (2002) - Infiltration theory for hydrologic applications. In: Smettem, K.R.J., Broadbridge, P., Woolhiser, D.A., (Eds.), Water Resources Monograph 15, American Geophysical Union, Washington, DC, $212 \mathrm{p}$.

Moody, J.; Kinner, D. e Úbeda, X. (2009) - Linking hydraulic properties of fire-affected soils to infiltration and water repellency, Journal of Hydrology, 379, Philadelphia, p. 291-303. 